\title{
Eat, drink and live merry?
}

\author{
G. R. Sridhar
}

Published online: 15 March 2011

(C) Research Society for Study of Diabetes in India 2011

Eat doesn't need explanation; drink doesn't always refer to alcohol; and live is the environment one resides. The parodied saying contains three of the crucial elements in our efforts to contain the diabetes juggernaut. Ten years after genomics threatened to overrun everything else, the excitement abated and clinical medicine still has the moorings in which it had evolved. This is nowhere more true than in diabetes mellitus.

To tackle obesity, insulin resistance and type 2 diabetes mellitus requires prevention by increasing the energy expenditure over the energy ingested, a straightforward thermodynamic principle that cannot be so easily translated to practice. Prevention studies all over the world have shown that increased physical exercise and appropriate nutrition are of prime importance. Theoretical underpinnings and now empirical data have suggested that built environment, or the environment in which people live is a principal facilitator or inhibitor of such behaviour.

The complex of obesity and diabetes mellitus is becoming more common, the primary reasons being environmental changes, of which stress and the consumption of food are important.

The prevalence of diabetes mellitus in rural India is lower than in the urban areas; in a study involving population above 24 years, (3294 men and 3714 women) the crude prevalence of diabetes was $2.8 \%$ (men at $3.31 \%$, and women $2.34 \%$ ). However, age-specific prevalence of diabetes between the ages of 45 and 64 was $4.69 \%$ [1].

G. R. Sridhar $(\bowtie)$

Endocrine and Diabetes Centre,

15-12-15 Krishnanagar,

Visakhapatnam, India

e-mail: sridharvizag@gmail.com
More bothersome, India is increasingly becoming urbanized along with the rest of the world [2]. The difference is only in degree and there is no convincing evidence that we will go against the trend.

Similarly, obesity is also becoming more common; Indians have the reputation of being 'thin but fat.' It is not commonly realized that obesity is more strongly linked to diseases than living in poverty, smoking or drinking [3].

Many layers of complex control exist to maintain body weight, making sustained weight loss difficult. Over evolutionary time, forces ensured an ability to conserve energy in times of fasting and feasting, which were the norm for most of mankind's existence. Unlimited availability of food without one having to work for it is a recent phenomenon.

Two studies published in the current issue of the Journal [4] focus on the environmental influences on food habits and bring out the awareness and subsequent possibility of promoting healthy lifestyle to prevent diabetes. Both were from major cities of India, Hyderabad and New Delhi. The results are distressing as far the attitudes and behavioural patterns go. In areas adjoining a large medical centre, prediabetes was identified in more than a quarter of subjects; it was associated with family history of diabetes, history of gestational diabetes, and increased birth weight. Therefore educational programme and appropriate built environment are essential components in halting the march to full fledged diabetes. Of equal if not greater concern is that South Delhi adolescents aged between 14 and 19 consumed less of healthy food such as fruits, greens and vegetables and relied on junk foods including carbonated beverages to satiate their hunger. They often missed breakfast, which worsened the situation. The type of residence also factored as a chief correlate in logistic regression analysis. 
It is being increasingly realized that availability of high calorie foods and sedentary habits form the chief underpinning of urban diabetes and obesity. Such behaviour, as the Delhi study showed, begins even at adolescence. Convenience, marketing and peer-pressure lead to increased intake of soft-drink and 'fast food.' Supermarkets and large malls increase potential access to fast foods, which could eventually spread even to rural areas. Access to food by itself is not bad if one understands that branding influences children's' taste perception and one can use branding to improve eating behaviour

Studies have shown that there is decreased energy expenditure with soft drinks than with milk. High sugar drinks do not induce satiety compared to milk, and fast foods simultaneously lead to increased calorie intake. This forms a vicious cycle leading to obesity.

The concept of built environment, defined as that including 'our homes, schools, workplaces, parks/recreation areas, business areas and roads...' [5] truly encompasses a range of physical and social elements that make up the structure of a community [6].

Just like how access to food can improve healthy eating, built environment must be developed to promote active living to prevent obesity and diabetes mellitus. Therefore modifying 'built environment' that helps physical activity is of foremost concern [7]. Recently we have shown that obesity was related to the kind of work, ability to relax, the access to afternoon nap and to psychosocial stress [8].

As elementary an advice is, asking individuals to go for walk has many potential barriers, viz the distance to cover (if the distance is too great, one tends to take a vehicle), the occurrence of steep slopes, which hinders one from walking, as well as the security issues particularly during night-time when going out to walk [9].

All these underline the principle that intervention strategies, whether applied to the environment or to a society may be targeted not just at single diseases but to the cluster of related conditions, obesity, hypertension and diabetes mellitus [10].

Population based interventions can adopt ways to disseminate information about the health benefits of proper eating, physical exercise and smoking cessation. Often the enticing advertisement for all that is unhealthy leaves no chance for healthy lifestyle to be adopted. Message of proper lifestyle can be spread by local social associations, the media or through food associations. It is also essential to make sure healthy food options are available at restaurants; food labeling is both educative and informative. In addition, face-to-face interactions about weight loss healthy diet, decreasing sodium intake and physical activity can be started. The message of healthy living gradually spreads by word of mouth.
Another important asset that is being squandered in modern society is sleep. Along with the development of urban areas, easy access to calorie dense food and ability to live by without physical exercise, the duration of sleep tended to decrease over time. A number of studies have evaluated the relation of sleep loss, appetite, obesity and diabetes mellitus. Biochemical parameters that could provoke obesity were found in association with inadequate sleep. Leptin, a well-known adipocyte signal to stop eating was shown to be lower with sleep deprivation. On the contrary, gherlin, the appetite signal was higher [11]. A variety of other factors are also believed to play a role including availability and craving for energy dense rich foods, especially for those who work night-shifts [12].

Is it really practical to avoid obesity, ranged as we are against evolution, biology and environmental pressures? Can the seemingly straightforward goal of decreased calories and increased physical exercise be put into practice? It may not be easy but it should not be impossible. Starting from basics, to lose $1 \mathrm{~kg}$ requires about 7,000-calorie negative balance: start with small steps of both, reduce the number of calories, and perform about 20-30 $\mathrm{min}$ a day of additional moderate exercise. This can be buttressed with behaviour modification techniques such as stimulus control, in which the factors leading to increased food intake are first identified and then measures are implemented to avoid or overcome the food-seeking behaviour. In addition it may help to make available low calorie foods in small amounts [13].

In addition, steps must be taken to lowering stress, or to lower the response to stress or both. Yoga is a practice that has been shown to do both [14]. If one has access to a properly trained Centre, that will help.

It is evident that there is what is called 'politics of obesity.' Improved prosperity increases obesity. Just as antibiotics by themselves did not improve the health and increase life expectancy, in recent years people did not suddenly become lazy and gorge themselves with junk foods. In a broader context, when people obtain extra income, they tend to use it to eat more and to be less active. Market economies encourage this. Gaining weight is good for business, both for the food industry and the health industry. Ultimately food is particularly big business because everyone eats [3].

Obesity has been called '..metaphor for the adverse health effects of economic and technological advancement' [15]. Even though 'obesity epidemic will not be cured in the consultation room' [16] one must at least begin somewhere. Why not start in the consultation room and watch it go out into the world! 


\section{References}

1. Sridhar GR, Rao PV. Prevalence of diabetes among rural Indians. In: Das S, editors. Medicine update. Assoc Physicians India Mumbai; 2003;13:370-3.

2. Kareiva P. Ominous trends in nature recreation. PNAS. 2008; 105:2757-8.

3. Hill JO, Wyatt HR, Reed GW, Peters JC. Obesity and the environment: where do we go from here? Science 2003;299:853-5.

4. Sharma R, Grover V, Chaturvedi S. Recipe for diabetes disaster: A study of dietary behaviors among adolescent students in south Delhi, India. Intn J Diab Dev Countr. 2011. doi:10.1007/s13410010-0009-8.

5. Srinivasan S, O'Fallon L, Dearry A. Creating healthy communities, healthy homes, healthy people: initiating a research agenda on the built environment and public health. Am J Public Health. 2003;93:1446-50.

6. Papas MA, Alberg AJ, Ewing R, Helzlsouer KJ, Gary TL, Klassen AC. The built environment and obesity. Epidemiol Rev. 2007;29:129-43.

7. Lavizzo-Mourey R, McGinnis JM. Making the case for active living communities. Am J Public Health. 2003;93:1386-8.

8. Sridhar GR, Sudhir Kumar P, Venkata P, Appa Rao A, Vijay K, Madhu K, Narasinga Rao MR, Kumar VK, Jiang Z, Lakshmi G. Built environment factors, psychosocial factors and Diabetes Mellitus: a south Indian study. Indian J Clin Med 2010;1:15-22.

9. Cervero R, Duncan M. Walking, bicycling, and urban landscapes: evidence from the San Francisco Bay area. Am J Public Health. 2003;93:1478-83.

10. Gaziano T, Reddy KS, Paccaud F, Horton S, Chaturvedi V. In: Jamison DT, Breman JG, Measham AR, et al., editors. Disease control priorities in developing countries, 2nd edition. Washington (DC): World Bank; 2006.

11. Taheri S, Lin L, Austin D, Young T, Mignot E. Short sleep duration is associated with reduced Leptin, elevated Ghrelin, and increased body mass index. PLoS Med. 2004;1(3):e62. doi:10.1371/journal.pmed.0010062.

12. Sridhar GR, Lakshmi G. Sleep and obesity. J Gen Med. 2009;21:54-6.

13. Sridhar GR. Childhood obesity. Indian J Practical Ped 2000;2:1217.

14. Kosuri M, Sridhar GR. Yoga practice in diabetes improves physical and psychological outcomes. Metab Syndr Relat Disord. 2009;7:515-7.

15. Kumanyika SK. The obesity epidemic: looking in the mirror. Am J Epidemiol. 2007;166:243-5.

16. Veerman JL, Barendregt JJ, van Beeck EF, Seidell JC, Mackenbach JP. Stemming the obesity epidemic: a tantalizing prospect. Obesity (Silver Spring). 2007;15:2365-70. 